\title{
A ESPIRITUALIDADE NO CONTEXTO DA EXPERIÊNCIA DO PACIENTE CIRÚRGICO - RELATO DE UM ESTUDO
}

\section{Denise Suzanna Siebert Hense*}

HENSE, D.S.S. A espiritualidade no contexto da experiência do paciente cirúrgico - relato de um estudo. Rev. Esc. Enf. USP, São Paulo, 23(3):329-336, dez. 1989.

Apresenta os resultados de uma pesquisa qualitativa que adotou a metodologia da teoria fundamentada nos dados para estudar a espiritualidade $e$ a experiência do paciente cinúrgico. Enfoca a subjetividade e o significado para o paciente da vivência de ter que ser operado, destacando o papel e a participação que nela tem a sua espiritualidade. Aponta algumas implicaçóes para a prática da enfermagem na assistência espiritual de paciente cirúrgico.

UNITERMOS: Espiritualidade. Paciente cirürgico.

\section{I - INTRODUÇÃO}

O estudo da experiência do paciente cirúrgico e de sua espiritualidade (HENSE, 1987) surgiu a partir da preocupação com a assistência de enfermagem adequada a ser prestada nesta situação de vida, com especial destaque ao que se refere à assistência espiritual. Lendo sobre o assunto percebe-se que muito pouco tem sido escrito sobre a espiritualidade do paciente hospitalizado. Os poucos estudos realizados verificam os aspectos relativos a ela apenas num momento de todo o período de hospitalização, não se preocuparam em ver como ela evoluia desde a internação até a alta hospitalar (ARAÚJO, 1976; HORIUCHI, 1982; MENEZES, 1975; FISCH \& SHELLY, 1978). Nos questionários e entrevistas utilizados predominavam questões fechadas elaboradas de acordo com um roteiro pré-estabelecido conforme as idéias que preliminarmente o autor já tinha. Isto pode ter limitado as respostas dos pacientes que participaram dos estudos, além de dificultar a identificação de algo novo quanto a espiritualidade, algo que até agora não fora percebido.

A consciência dessa situação, somada ao interesse pelos aspectos relativos à espiritualidade, é que me levaram a tentar outro tipo de estudo. Um estudo onde

\footnotetext{
* Graduada em Enfermagem pela UFSC, Licenciada em Enfermagem pela URGS, Mestre em Ciências da Enfermagem pela UFSC.
} 
iria além de entrevistar ou solicitar que o paciente respondesse um questionário, conversar e conviver com ele e com a equipe que o assiste no transcorrer do período de hospitalização. Meu desejo era ouvir o que ele tinha a me contar de sua experiência como paciente cirúrgico e de sua espiritualidade naquela situação de vida. Queria estar aberta para eventuais novos aspectos que pudessem ser mencionados por eles e que até então não haviam sido identificados noutro estudo.

\section{II - METODOLOGIA}

Para ser coerente com a proposta do estudo, a metodologia a ser utilizada só poderia ser qualitativa (GLASER \& STRAUSS, 1967; CHENITZ \& SWANSON, 1986; LUDKE \& ANDRÉ, 1986; STERN, 1980), que difere em vários pontos da metodologia quantitativa, tradicional e amplamente utilizada nos estudos científicos. Uma metodologia qualitativa prioriza a convivência com as pessoas que participam do estudo, para que se possa aprender o máximo de sua experiência, dos seus sentimentos, de suas opiniōes e dos fatos envolvidos. É importante sentir com elas e viver com elas sem no entanto perder a visão objetiva de pesquisador. Uma pesquisa qualitativa não utiliza caracteristicamente a análise estatística dos dados obtidos junto aos informantes, como é o caso da metodologia quantitativa. A análise é muito mais um processo mental pelo qual passa o pesquisador ao coletar e refletir sobre os dados ao comparar entre si todas as informaçōes coletadas.

Os dados do presente estudo foram coletados junto a pacientes cirúrgicos previdenciários e particulares, submetidos à cirurgias consideradas necessárias, de pequeno e médio portes, num hospital de uma cidade de Santa Catarina nos meses de abril a dezembro de 1985. Foram selecionados três diferentes grupos de pacientes, que juntos totalizaram numa amostra de 31 pacientes. Para coletar os dados foi utilizada a observação participante que no caso deste estudo foi desenvolvida através de técnicas como a observação, a entrevista com o paciente e equipe de saúde, participação na assistência e consulta ao prontuário. A análise dos dados, que se deu de forma integrada e simultânea com a coleta dos dados, foi feita através da constante comparação dos dados para que assim se pudesse ir gradativamente construindo um esquema que representasse a experiência e a espiritualidade do tipo de pacientes em estudo.

\section{III - RESULTADOS}

O que é a espiritualidade do paciente cirúrgico? Como ele mesmo a entende? Como ele a vive na situação de doença, hospitalização e cirurgia? Qual seu papel dentro da experiência vivida?

Antes de responder a estas perguntas norteadoras são necessárias algumas considerações. São três os aspectos experimentados na etapa preliminar do estu- 
do e que gostaria de destacar. Primeiro: há diferentes maneiras de entender-se o que seja "espiritualidade". A idéia a respeito dela varia de pessoa para pessoa. Algumas pessoas, por exemplo, a entendem como transcendência ou energia; outros como princípio de vida ou código de ética, filosófico ou moral; outros ainda como questionamentos e problemáticas que envolvem a existência, a natureza, o destino, a vida e a morte; há também os que se referem a ela como sistema de crenças ou crença no sobrenatural. Para os cristãos, ela está centralizada em Deus, Jesus Cristo e no Espírito Santo. Segundo: a espiritualidade não envolve apenas o que pensamos a seu respeito, mas principalmente como a vivemos. É na nossa experiência diária que realmente revela-se o que ela significa para nós, pois nem sempre o que pensamos evidencia-se na prática. Terceiro: é impossível separar a espiritualidade dos outros aspectos que formam a nossa vida, das nossas experiências diárias e da situação que estamos vivenciando. Temos que entendê-la dentro deste contexto.

Ao iniciar o estudo pensava em estudar somente a espiritualidade. No entanto ao começar a coletar os dados percebi que não poderia fazê-lo sem entender primeiro o que significa para o paciente estar doente, ser hospitalizado e ser operado. Percebi que, apesar de sempre ter falado e pensado na espiritualidade como algo ligado à nossa experiência diária, na hora de estudá-la eu estava querendo separá-la da experiência vivida pelo paciente naquela situação. Vi que para entender verdadeiramente o que significa a espiritualidade para o paciente teria que considerar seu contexto de vida, para assim poder ir além do que ele fala sobre ela, mas verificar também como ele a vive. Tive também que reconhecer que, apesar de querer estar aberta para o que o paciente me dizia, eu também tinha certas idéias preliminares quanto a espiritualidade - sou cristã e não poderia deixar de sê-lo. Tinha que, no entanto, tomar cuidado para não inferir ou interpretar as informações que coletava junto ao paciente. Não era meu papel julgá-lo, mas sim entendê-lo. Por isso, também aqui nesse texto, é necessário que primeiro entendamos o que é ser um paciente cirúrgico, como ele mesmo vive e sente a experiência de doença, hospitalizaçāo e cirurgia.

Para o paciente esta é uma situação que se caracteriza fortemente pela sensação de obrigatoriedade, de pressão, ou de sentir-se forçado. Ele não deseja operar, ele "tem que" operar. Por isso, pode-se dizer que no seu todo essa é uma situação percebida como "Tendo que Operar-se". Isso é verdade desde o momento em que surgem as manifestações de alteração na saúde até a alta hospitalar, passando por experiências como "ter que" ir ao médico, "ter que" internar e "ter que" submeter-se a cirurgia. $\mathrm{O}$ "Tendo que Operar-se" expressa a experiência global do paciente e envolve três diferentes vivências. Primeiro: as vivências físicas, como a dor, as náuseas, a falta de apetite, a indisposição física que em maior ou menor grau "tem que" ser vividas pelo paciente. Segundo: as vivências consideradas mentais ou racionais e que envolvem tudo o que o paciente pensa ou faz para di- 
minuir ou acabar com os problemas ou dificuldades encontradas. Terceiro: as vivências relacionadas mais especificamente com os sentimentos, emoçōes e sensações experimentadas pelo paciente, como é o caso do medo, da agonia, da preocupação e do nervosismo.

"Tendo que Operar-se" é sem dúvida uma experiência difícil e desagradável para o paciente. Percebe-se, no entanto, que no seu transcurso ele utiliza maneiras de aliviar a dificuldade presente. São recursos que amenizam a experiência para ele, mas que nunca chegam a contrabalançá-la. São três ao todo. Primeiro: buscar e encontrar uma explicação para o fato da doença e a cirurgia terem acontecido com ele. Geralmente, conhecer os fatores que levaram ao surgimento da doença e encontrar um significado transcendental na experiência o deixa mais tranqüilo. Segundo: confiar na equipe de saúde, em si e principalmente em Deus. A confiança gera nele uma certa sensação de certeza e segurança. Terceiro: ter a ajuda das pessoas e de Deus. As pessoas a sua volta e Deus podem dar-lhe auxílio, amparo, proteção e força.

Agora, depois de ter uma idéia de como o paciente vive o fato de estar doente, de "ter que" ser hospitalizado e operado, é que se pode explorar mais de perto sua espiritualidade. A idéia que o paciente, de forma geral, tem de sua espiritualidade, é que ela é algo estreitamente ligado à sua vida religiosa. É essencialmente ali que ela se manifesta. Convivendo com ele, no entanto, percebe-se algo mais que isso. Vale ressaltar que os pacientes que participaram do estudo eram ou católicos ou evangélicos e, em maior ou menor grau, tinham algum tipo de prática religiosa. Não eram diferentes da maioria dos brasileiros.

Observando, conversando e refletindo sobre a espiritualidade do paciente cirúrgico do presente estudo, percébe-se que o aspecto mais significativo que transparece é a busca e o "reconhecimento de um ser superior". É basicamente dessa forma que ele vive em sua espiritualidade desde a manifestação da alteração na saúde até a alta hospitalar. É bastante comum ele buscar uma maior proximidade com Deus, com Jesus, com Maria e com os Santos. Especialmente Deus tende a ser percebido como tendo o poder supremo. Muitas vezes um último recurso, alguém que ainda pode fazer algo quando ninguém mais pode.

O "reconhecimento de um ser superior" ameniza a experiência para o paciente cirúrgico já que Deus geralmente está de alguma forma associado a explicação encontrada para o fato de estar vivendo tal situação, é nele também que ele deposita sua maior confiança e encontra o apoio ou ajuda espiritual desejada.

O "reconhecimento de um ser superior" expressa o todo do que é para o paciente cirúrgico sua espiritualidade e envolve quatro aspectos distintos. $\mathrm{O}$ primeiro, já mencionado, é aquele que se refere ao aspecto mais oficial, tradicional ou institucionalizado, sua "afiliação religiosa". Inclui sua denominação religiosa; seus hábitos religiosos como ler a Bíblia, ir à missa ou ao culto, fazer novena, re- 
zar e confessar; e os relacionamentos eclesiásticos que costumeiramente são mantidos com o padre/pastor, com amigos da igreja e com a igreja em si. Segundo: o "reconhecimento de um ser superior" também pode ser identificado noutro aspecto, na "busca de um significado" para a doença, cirurgia e sofrimento. Pensar que a doença é algo que pode levar para mais perto de Deus, que ela é uma forma de Deus nos chamar, que "ele permite a doença e a cirurgia para que nos tornemos mais crentes", são idéias que tranqüilizam o paciente ao lhe dar uma perspectiva transcendental para o que está acontecendo. $O$ terceiro aspecto refere-se ao "apoio e a retaguarda espiritual" desejados e experimentados pelo paciente. Deus, Jesus, Maria e os Santos são para ele uma importante fonte de auxílio, proteção e força. Envolve os pedidos de cura e sucesso na operação; a força obtida de símbolos religiosos como um crucifixo; o preparo interior do paciente expresso nas novenas, na confissão, na leitura da Bíbỉa, na Comunhão ou Santa Ceia. Também inclui as condições que ele recebe de Deus para enfrentar as dificuldades, como coragem e paciência. Deus também pode intervir acabando com a dificuldade, como por exemplo, acabando com a dor sentida. $O$ auxílio espiritual também pode ser recebido de outras pessoas através de suas orações e seus conselhos. $\mathrm{O}$ quarto e último aspecto identificado como parte de "reconhecimento de um ser superior" está relacionado com a "confiança" que ele tem nesse ser superior. Ela engloba a constante lembrança de Deus, a crença ou fé nele, o apego a Deus, Jesus, Maria e aos Santos, a entrega a Deus e aceitação de sua vontade como a melhor.

O "reconhecimento de um ser superior" é algo que está presente no transcorrer de toda a experiência do paciente cirúrgico, desde que ele percebe a alteração na sua saúde até a alta hospitalar. É necessário, no entanto, ressaltar que cada um dos quatro aspectos mencionados tende a se evidenciar em diferentes momentos da experiência. Os aspectos relacionados a "afiliação religiosa" tendem a estar mais evidentes quando ele ainda está em casa. É quando seus hábitos religiosos e relacionamentos eclesiásticos se intensificam, pois, com a internação estes são muitas vezes dificultados. Os aspectos relacionados a "busca de significado", "apoio ou retaguarda espiritual" e "confiança", por sua vez tendem a se evidenciar desde o momento em que ele recebe a notícia da necessidade da cirurgia até o momento de sua realização. É enquanto espera ser operado que ele mais busca o apoio de um ser superior. É nessa época que ele mais se apega à fé em Deus, ao auxílio, à força e à proteção que Deus pode lhe dar e ao significado nele encontrado para o fato de estar vivendo uma situação difícil.

Além disto é necessário ressaltar que a intensidade com que cada paciente experimenta cada um dos aspectos mencionados pode variar. Um paciente pode, por exemplo, expressar o "reconhecimento de um ser superior" mais através da "afiliaçâo religiosa", enquanto outro, através do "apoio ou retaguarda espiritual". Alguns demonstram claramente o vínculo e apego a Deus. Outros, apesar 
de lembrarem de Deus e rezarem demonstram uma aparente indiferença fazendo brincadeiras sobre a morte e sobre Deus, ou então, mostrando-se seguros do sucesso da cirurgia.

Percebe-se que o "reconhecimento de um ser superior" é algo que tende a se tornar mais forte na dificuldade, nos momentos em que o paciente sente-se com menos poder e em maior risco de vida como quando no centro cirúrgico. Paralelamente também nota-se que esse reconhecimento está relacionado à experiência passada do paciente. O tipo de vínculo que ele mantinha com Deus no passado, antes de adoecer, influencia sua experiência com Deus quando doente e hospitalizado. $O$ paciente que costumava manter um relacionamento pessoal e constante com Deus tende a encontrar nele uma maior confiança, ajuda e sentido nesta situação.

\section{IV - IMPLICAÇÕES}

Mas... o que tudo isto tem a ver com a nossa prática na assistência ao paciente? Bem, primeiramente esta é a maneira de ele viver e pensar sua espiritualidade. Talvez diferente da maneira como nós vivamos a nossa, ou da maneira como nós acreditamos que ele viva a dele. Por isso, se quizermos auxiliar o paciente e assistí-lo de forma integral, sem excluir sua espiritualidade, é necessário que nos aproximemos dele considerando que sua espiritualidade se manifesta na forma do "reconhecimento de um ser superior" e dos quatro aspectos que o compõe.

Vamos refletir agora especificamente nas aplicações que o conhecimento gerado pelo presente estudo pode ter na prática da enfermagem. Apesar de caber ao capelão e ao ministro religioso a assistência espiritual especializada, o enfermeiro não está isento de atuar junto com eles num trabalho integrado, incluindo a espiritualidade do paciente na utilização e desenvolvimento da metodologia de assistência adotada. Dentro dessa perspectiva sugere-se que:

19) no histórico de enfermagem seja considerado o levantamento dos dados no que se refere aos quatro componentes do "reconhecimento de um ser superior" (quadro no 1);

$2^{2}$ ) no transcurso da experiência do paciente cirúrgico, desde a manifestação da alteraçāo na saúde até a alta hospitalar, seja considerado que o "reconhecimento de um ser superior" apresenta mudanças no tempo, devendo-se por isso, a cada momento, prestar especial atenção aos aspectos que naquela ocasião tendem a se evidenciar;

39) seja verificado como o paciente está vivendo toda a situação percebida como "Tendo que Operar-se" e os meios utilizados para amenizá-la;

49) o planejamento da assistência espiritual seja flexível e inclua metas que direcionem a conduta da equipe de enfermagem nas oportunidades de contato e nos momentos de crise, para garantir a continuidade da assistência; 
59) na implementação seja considerado que cada paciente é único e que por isso ações esteriotipadas devem ser evitadas, onde a oração, a Bíblia e o encaminhamento ao ministro religioso devem ocorrer de acordo com a situação pessoal de cada paciente; e que

69) o enfermeiro avalie e tenha sempre em mente as características de sua própria espiritualidade para evitar confundí-la com a do paciente e provocar distorçōes na avaliação e no planejamento da assistência a ser prestada ao paciente.

\section{Quadro no 1}

Aspectos a considerar no levantamento de dados relacionados à espiritualidade do paciente cirúrgico que submete-se à cirurgias necessárias de pequeno e médio portes.

\section{ESPIRITUALIDADE: "Reconhecimento de um Ser Superior'”}

1. "Afiliação Religiosa": denominação religiosa, história religiosa, hábitos e práticas consideradas importantes, evidência de alguma prática religiosa, relacionamentos eclesiásticos considerados importantes, significado da religião, significado e importância de Deus, Jesus, Maria e dos Santos.

2. "Busca de um Significado": participação que a religião, Deus ou outro ser considerado superior tem no significado da doença, cirurgia, sofrimento, objetivo da vida, desenvolvimento de suas atividades e comportamento; influência principal de Deus na vida.

3. "Apoio e Retaguarda Espiritual": relacionamento que mantém com Deus, cuidado e proteção sentidos, o que o faz sentir cuidado por Deus, apoio espiritual dado por outros, visita do padre/pastor/leigos.

4. "Confiança": lembrança de Deus, características da crença em Deus ou em outro ser considerado superior, apego a Deus, Jesus, Maria e aos Santos, maneira e a quem se entrega quando em dificuldade.

5. Síntese:

- significado da prática religiosa;

- conceito de Deus e/ou de outro ser considerado superior;

- influência e características gerais da participação de Deus ou de outro ser considerado superior na explicação dada para a situação vivida, na ajuda recebida e na confiança sentida. 
HENSE, D.S.S. The spirituality in the context of the experience of the surgical patient: report on a study. Rev. Esc. Enf. USP, São Paulo, 23(3):329-336, dec. 1989.

This article presents the results of a qualitative research which adopted the Grounded Theory Methodology to study the surgical patient's spirituality and experience. It focuses on the subjectivity and the meaning of the surgical experience of the patient having to submit to a surgery, while distinguishing the role and the participation of his spirituality in the experience. It points out same implications for surgical nursing in spiritual assistance to the patient.

UNITERMS: Spirituality. Surgical patient.

\section{REFERÊNCIAS BIBLIOGRÁFICAS}

ARAÚJO, C.P. de. Estudo sobre a necessidade religiosa de pacientes em fase pré-cinúrgica. São Paulo, 1976. 39 p. (Dissertação de mestrado - Escola de Enfermagem da USP).

FISH, S. \& SHELLY, J. Spiritual care: the nurse's role. Downers Graves, Intervarsity, 1976.

GLASER, G.B.\& STRAUSS, A.L. The discovery of grounded theory: strategies for qualitative research. New York, Aldine, 1967.

CHENITZ, W.C. \& SWANSON, J.M. From practice to grounded theory: qualitative research in nursing. California, Addison-Wesley, 1986.

HENSE, D.S.S. Tendo que operar-se: a experiência do paciente cirúrgico e sua espiritualidade. Florianópolis, 1987. (Dissertação de mestrado - Faculdade de Enfermagem da UFSC).

HORIUCHI, L.N.O. Problemas biopsicoespirituais mais sentidos pelos pacientes submetidos a procedimentos diagnósticos - subsídios para açōes de enfermagem. Rio de Janeiro, 1982. 93 p. (Dissertação de mestrado - Escola de Enfermagem Ana Neri da UFRJ).

LÜDKE, M. \& ANDRÉ, M.E.D.A. Pesquisa em educação: abordagens qualitativas. São Paulo, EPU, 1986.

MENEZES, A.R. A problemática da enfermagem dos pacientes no período trans-operatório - um estudo dos problemas sentidos e observados. São Paulo, 1978. 81 p. (Dissertaçăo de mestrado - Escola de Enfermagem da USP).

STERN, P.N. Grounded Theory methodology: its uses and processes. Image, New York, 12(1): 20-3, Fev. 1980.

Recebido em 07/04/88 